\title{
Privatização das políticas educacionais no Brasil: uma análise do censo IBGE-IPEA 2005 das Fundações e Associações Sem Fins Lucrativos (FASFIL).
}

\author{
Privatization of educational policies in Brazil: \\ an analysis of the IBGE-IPEA 2005 census of \\ Foundations and Associations Without Finally \\ Profit (FASFIL)
}

\section{Privatización de las políticas educativas em Brasil: análisis del censo IBGE-IPEA 2005 de las Fundaciones y Asociaciones Sin Fines de Lucro (FASFIL).}

Marcelo Paula Melo*

Bruno Adriano Rodrigues da Silva**

\begin{abstract}
Resumo: Estão em curso formas variadas de privatização da oferta do direito à educação. Uma delas envolve a intensa atividade de organizações da sociedade civil, normalmente caracterizadas como sem fins lucrativos, em formas de convênios com entes estatais. O objetivo desse artigo é analisar dados do Censo das Fundações e Associações Sem Fins de Lucro produzido pelo Instituto Brasileiro de Geografia e Estatísticas em parceria com o Instituto de Pesquisas Econômicas e Aplicadas no ano de 2005, particularmente aqueles oriundos das subdivisões da grande área Educação e Pesquisa: educação infantil, ensino fundamental e médio (educação básica). Organizamos os dados disponíveis no censo considerando as regiões do país, as décadas de criação das FASFIL, o número de trabalhadores, a média salarial nas FASFIL, entre outros. Eles foram descritos por meio de tabelas e cotejados com referências bibliográficas sobre a política educacional. Concluímos que a expansão do número, o aumento da
\end{abstract}

\footnotetext{
* Doutor em Serviço Social pela UFRJ (2011), mestre em Educação pela UFF (2004) e graduado em Educação Física pela UFRJ (2001). Docente na Escola de Educação Física e Desportos e no PROGRAMA DE PÓS GRADUAÇÃo EM EDUCAÇÃO na UFRJ. Líder do grupo de Pesquisa Coletivo de Estudos de Políticas de Esportes, lazer e Educação Física (GEPOLES). E-mail: marcelaomelo@gmail.com.

** Doutor em Educação pela UFRJ (2013), mestre em Educação pela Unirio (2008), graduação em Educação Física e Desporto pela UFRJ. Professor Adjunto da Unirio. E-mail: b.adriano_rs@yahoo.com.br.
}

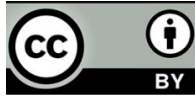


amplitude e o crescimento vertiginoso da capacidade de atuação das FASFIL integraram o desenvolvimento do projeto neoliberal que confere novas características as relações público-privadas na oferta do direito à educação.

Palavras chave: Fundações e Associações sem Fins Lucrativos (FASFIL); neoliberalismo; direito à educação, privatização.

Abstract: Various forms of privatization in the right to education's offer
are underway. One of them involves an intense activity of civil association,
normally characterized as non-profit, in the form of agreements with state
entities. The purpose of this article is to analyze data from the Census of Non-
Profit Foundations and Associations produced by the Brazilian Institute of
Geography and Statistics in partnership with the Institute of Economic and
Applied Research in 2005, particularly from the subdivisions of the large area
of Education Research: early childhood education, elementary and high school
(basic education). We organized the data available in the census considering
the regions of the country, the decades of creation of FASFIL, the number of
workers, the average salary in FASFIL, among others. They were described
using tables and collated with bibliographic references on educational policy.
We conclude that the expansion of the number, the increase in breadth and the
vertiginous growth of the FASFIL's capacity to act integrate the development
of the neoliberal project that confers new characteristics such as public-
private relations in the offer of the right to education.

Keywords: Fundações e Associações sem Fins Lucrativos (FASFIL); neoliberalism, right to education and privatizacion.

Resumen: Se están llevando a cabo diversas formas de privatización de la oferta del derecho a la educación. Uno de ellos involucra la intensa actividad de las organizaciones de la sociedad civil, normalmente caracterizadas como sin fines de lucro, en forma de convenios con entidades estatales. El propósito de este artículo es analizar los datos del Censo de Fundaciones y Asociaciones sin Fines de Lucro elaborado por el Instituto Brasileño de Geografía y Estadística en asociación con el Instituto de Investigaciones Económicas y Aplicadas en 2005, particularmente los de las subdivisiones de la gran área Investigación Educativa: educación infantil, primaria y secundaria (educación básica). Organizamos los datos disponibles en el censo considerando las regiones del país, las décadas de creación de FASFIL, el número de trabajadores, el salario promedio en FASFIL, entre otros. Se describieron mediante tablas y se compararon con referencias bibliográficas sobre política educativa. Concluimos que la expansión del número, el aumento de la amplitud y el vertiginoso crecimiento de la capacidad de acción del FASFIL son parte del desarrollo del proyecto neoliberal que da nuevas características a las relaciones público-privadas en la oferta del derecho a la educación.

Palabras clave: Fundações e Associações sem Fins Lucrativos (FASFIL); neoliberalismo, Derecho a la education y privatización. 


\section{Introdução}

A promulgação da Carta Constitucional de 1988 ficou marcada como um memorável evento histórico brasileiro, ao apontar para uma quadra de embates políticos após duas décadas de ditadura civil-militar. Porém, enquanto a conjuntura brasileira parecia indicar uma incipiente redemocratização, o projeto capitalista neoliberal de desenvolvimento fincava suas bases nos países centrais e avançava para se estabelecer em outras formações sociais capitalistas dependentes. As eleições de projetos abertos ou dissimuladamente neoliberal em diversos países da América Latina ao longo dos anos 1980 e início dos 1990 são marcas potentes desse percurso. Seus nomes, partidos políticos e ações estão documentadas na história de cada país do continente.

A perspectiva neoliberal de gestão do Estado foi lentamente adotada pelos governos brasileiros pós 1988 e refletiu na produção de políticas públicas que se distanciaram evidentemente da perspectiva universalista de garantia de direitos sociais. O projeto capitalista neoliberal conta com ampla propaganda em virtude de uma depreciação da ação estatal como contraponto a uma suposta e intrínseca maior qualidade da ação privada mercantil e \ou por organismos na sociedade civil. Estamos diante de um projeto histórico da classe burguesa em nível mundial, com suas variantes e particularidades em cada formação social, com vistas a reafirmar seu poder de classe e viabilizar a extração do lucro via aumento da exploração do trabalho e da natureza em níveis que julgávamos terem sido deixados no século XIX.

Com base em pesquisas sobre a política educacional podemos afirmar que estão em curso na atualidade, como parte do neoliberalismo, formas de privatização da oferta do direito à educação devido à intensa atividade de organizações da sociedade civil, caracterizadas formalmente como sem fins lucrativos, tanto no que se refere à Educação Básica, como à Educação Superior (SAVIANI, 2007; SHIROMA, GARCIA, CAMPOS, 2011; MARTINS, 2008; MANCEBO, VALE, MARTINS, 2015).

Por isso, a reforma do Estado neoliberal - processo ainda em curso no Brasil e em outros países - inclui ao lado da cobrança clássica por serviços, a privatização de novo tipo que inclui o acesso ao fundo público como forma de garantir a lucratividade na oferta de políticas públicas. A utilização de organizações supostamente sem fins de lucro na execução dessa politicas foi um ponto presente na formulação de diversos intelectuais orgânicos da burguesia, tanto em nível nacional, como internacional. Reportagens jornalísticas em diversos meios, atuação de organismos internacionais por meio da produção de documentos, publicações e cursos, a atuação de organizações empresariais e de parlamentares pelas chamadas parcerias, concessões e publicizações de órgãos estatais foram evidenciam o projeto neoliberal no Brasil (MELO, 2018).

Não por acaso, estas organizações ditas acima, estão expressas em normatizações jurídicas que regulamentam suas atuações, tais como: Organizações Sociais (OS), Lei Federal 9.637 de 15 de maio de 1998; e Organizações da Sociedade Civil de Interesse Público (OSCIP), Lei Federal 9.790 de 23 de março de 1999 (BRASIL, 1998; BRASIL, 1999).

As OS e OSCIP executam políticas públicas, mediante contratos de gestão e termos de parceria, e se tornam entes importantes nesta dinâmica, ainda que não por acaso, pouco visíveis à população usuária. Aprofundando a lógica privatista de atuação estatal, ao longo dos anos 2000 foram aprovadas uma série de legislações que regulamentavam as OS e OSCIP nos estados e, sobretudo, nos municípios, provendo-lhes condições legais para responder às demandas de privatização de políticas sociais locais.

A partir desse quadro apontado, o objetivo desse artigo é analisar os dados do Censo das FASFIL produzido pelo Instituto Brasileiro de Geografia e Estatísticas (IBGE) em parceria com 
o Instituto de Pesquisas Econômicas e Aplicadas (IPEA) no ano de 2005, quando foi revelada a existência 338.162 FASFIL divididas em 10 grandes áreas (com suas subdivisões). ${ }^{1}$ Interessa-nos a grande área Educação e Pesquisa, particularmente as subdivisões relativas à educação básica (infantil, fundamental e médio).

Para cumprirmos tal análise, organizamos os dados disponíveis no censo considerando as regiões do país, as décadas de criação das FASFIL, o número de trabalhadores, a média salarial nas FASFIL, entre outros. Tais dados foram descritos por meio de tabelas e cotejados com referências bibliográficas sobre a política educacional.

A análise do impacto das FASFIL na sociedade brasileira (e quiçá, mundial) precisa incluir seu papel de empregadores de larga escala de força de trabalho (MELO, 2018). Isso implica maiores desafios à luta contra a privatização das políticas sociais.

Acreditamos que o crescimento de FASFIL, muitas já criadas para estabelecer relações com órgãos estatais, por meio de políticas públicas de diversas naturezas, atesta a preocupação do bloco no poder em garantir constantemente o consenso ativo dos trabalhadores e trabalhadoras, tanto os atendidos pelos programas executados por FASFIL (ainda que com financiamento público), quanto aqueles que nelas trabalham diretamente (MELO, 2018). Isso não implica em uma ampliação da ação estatal e menos ainda na maior universalização dessas políticas sociais.

As novas expressões da relação público-privado ou estatal-civil como soma de interesses (supostamente) convergentes, até mesmo eliminando a possibilidade de divergência e antagonismos de projetos e concepções de mundo, implicam em uma pedagogia contraditória. Assim, a dita promoção da cidadania, tão em voga em pronunciamentos de sujeito políticos radicados com interesses dos mais díspares possíveis, é louvada como algo não político ou mesmo apolítico, implicando em programas estatais ou privados de "socorro ou prevenção do transbordamento dos problemas sociais" (PAOLI, 2007, p. 232)

A realização das atividades de um conjunto de FASFIL obrigatoriamente implica na “(...) conciliação com os imperativos mercantis, financeiros e estatais, dentro dos quais a noção de ‘público' se torna bastante elástica”. De um mesmo modo que “(...) impedem que a população receptora dos bens resultantes de tais práticas elabore qualquer outra compreensão desses atos para muito além do tradicional modo heteronômico de entender o gesto doador de salvação (...)" (PAOLI, 2007, p. 232).

\section{Transformações na relação público-privado na história da educação brasileira.}

No Brasil a educação escolar realizada de modo privado, seja apenas por indivíduos ou por instituições privadas, historicamente, foi reconhecida, autorizada e incentivada pelo Estado. Face ao contexto ocorriam transformações nesta relação, algo que reverbera até as suas formas mais atuais (CURÁ, 2008). o lento, mas progressivo, processo de urbanização e industrialização a partir

\footnotetext{
${ }^{1}$ Tal pesquisa censitária foi realizada a partir do Cadastro Central de Empresas (CEMPRE) do Ministério da Fazenda e da inscrição das organizações no Cadastro Nacional de Pessoa Jurídica (CNPJ) por conta de suas atividades econômicas. 0 CEMPRE é atualizado anualmente, juntamente com outros dois importantes indicadores do Ministério do Trabalho e Emprego: a Relação Anual de Informações Sociais (RAIS) e o Cadastro Geral de Empregados e Desempregados (CAGED). A partir do código de natureza jurídica no CEMPRE foi possível determinar o campo de atuação das FASFIL. Este é composto de 16 subdivisões no universo de atuação das FASFIL, ainda que nem todas recebam essa denominação. Outros três Censos foram produzidos: dados de 2000 publicados em 2002; dados de 2008 publicados em 2010; e dados de 2016 publicados nesse mesmo ano.
} 
das décadas iniciais do século XX iniciou timidamente, e com franco atraso em relação a outros países, mesmo da América Latina, uma presença mais sistemática da oferta estatal de Educação.

A ampliação da escolarização das classes populares, nesse sentido, não era o assunto principal da pauta educacional das classes dominantes brasileiras nas décadas iniciais do século XX. Isso expressa que o acesso à educação, historicamente, mesmo quando oferecido pelo Estado, viabilizou oportunidades educacionais que foram concentradas nas classes dominantes e obviamente isso criou uma fenda que separava aqueles que tinham e os que não tinham acesso à educação por meio de instituições escolares.

Por outro lado, especialmente a partir dos anos 1930, o chamado "período Vargas" que vai até 1945 , houve uma expansão tímida do direito à educação, pois era necessária ao cenário industrial que se desenhava nos grandes centros urbanos a expansão dos níveis, etapas e modalidades educacionais, em especial, na região sudeste do país, mas não só. Tal processo contemplava os interesses diversos das classes e frações da classe dominante (industrial, agrária e financeira, principalmente) que controlavam o Estado brasileiro.

Destacamos no período dito acima a: i) "reforma Francisco Campos" que, após a criação do Ministério da Educação e Saúde Pública (1931), organizou a educação nacional por meio de decretos que criavam o Conselho Nacional de Educação (órgão responsável pelas questões da educação em todo território nacional), o Estatuto das Universidades Brasileiras, a Universidade do Rio de Janeiro e o ensino secundário e comercial; ii) "reforma Gustavo Capanema" modificava o ensino superior (1934), o industrial e secundário (1942), comercial (1943), normal, primário e agrícola (1946) complementados pela criação do Senai e Senac (1946); e o Manifesto dos Pioneiros da Educação Nova (1932) que levantou a bandeira política da educação pública, laica, para todos, inclusive para as classes populares, naquele contexto (SAVIANI, 2004).

Ao fim desse período de estruturação do Estado em matéria de Educação, novamente, vieram à tona as discussões sobre a atuação privada na oferta do direito e a predominância de seus interesses, em função da demanda constitucional acerca de uma legislação específica para a educação (CF 1946, art. 5, inciso XV, letra d). Foram colocados em questão aspectos referentes aos níveis, etapas e modalidades da educação: a escola secundária, apenas humanística e por consequência capaz de distinguir as frações dominantes que a frequentava visando o acesso ao ensino superior; e a escola profissional e humanística também no secundário que aliava a formação cultural à profissional, com o objetivo de democratizar o seu acesso às outras classes sociais (XAVIER, 2003).

A definição das funções do Estado foi um dos eixos em torno da relação público e privado. O que prevaleceu com a Lei de Diretrizes e Bases (LDB) de 1961 foi uma relativa ampliação das oportunidades escolares às classes populares, comparadas à conjuntura anterior, embora monstruosamente atrasada em face de outros países. A manutenção do acesso ao fundo público como forma de privatização da Educação foi mantida e promovida. Essa legislação previa o repasse de recursos públicos às escolas privadas via concessão de bolsas de estudos, além de subvenções e repasses via cooperação técnica e financeira entre a União, estados e municípios (SAVIANI, 1998).

Essa ordem foi aprofundada com o início em 1964 da ditadura civil-militar (FRIGOTTO, 2003). As reformas no ensino superior, secundário e primário apenas aprofundaram o quadro de privatização na oferta do direito à educação, com tímida expansão da rede estatal. Os crescentes números de matrículas nas instituições privadas de ensino, notadamente no ensino secundário e superior, nesse contexto, evidenciam isso. Os caminhos educacionais duais e restritivos às classes populares eram garantidos via oferta mínima de escola pública em níveis mais avançados, 
pouquíssimas políticas de permanência nas escolas e o encaminhamento precoce ao chamado secundário profissionalizante (CUNHA, 1980).

As formas de privatização da educação não foram extintas com o fim da ditadura civil-militar (FRIGOTTO, 2003); ao contrário, elas foram transformadas. A sangria provocada pela transferência dos recursos do Salário-Educação ${ }^{2}$ diretamente às escolas privadas, porta de entrada de monstruosas fraudes, bem como o incremento profundo do fundo público como garantidor da lucratividade, mesmo escondida sob o suposto filantropismo confessional ou não, são evidências dessa transformação. A conjuntura da aprovação da Constituição de 1988 e da Lei de Diretrizes de Bases em 1996 não encontrou força suficiente nos trabalhadores organizados para barrar os mecanismos privatizantes no âmbito da oferta do direito à educação. Contrariamente, notamos um incremento e uma variabilidade das formas, programas e mecanismos que, diretamente e indiretamente, garantiam a predominância dos interesses privados no campo da educação (PINTO, 2016; DAVIES, 2000).

A despeito das mobilizações dos trabalhadores, a fração burguesa brasileira e internacional (naquele momento ainda com tímido processo de internacionalização, algo que explodiria nos anos 2010) que atuava no campo educacional em função das privatizações não foi derrotada diante da LDB de 1996, afinal, os mecanismos que viabilizavam o acesso ao fundo público por escolas privadas continuavam presentes. $O$ art. 7 conferia liberdade de atuação às instituições de ensino da iniciativa privada, com algum nível de regulação estatal e o art. 20 categorizava essas instituições em confessionais, comunitárias e filantrópicas, para usarmos os termos presentes na lei geral da educação. Ademais, os estudiosos do financiamento da Educação denunciavam, à época, manobras contábeis que escondiam a finalidade lucrativa dessas instituições (DAVIES, 2000).

As reformas educacionais do Governo Covas (1995-1998) realizadas no estado de São Paulo sistematizaram e puseram em marcha os pressupostos fixados na LDB, evidenciando e materializando as formas privatizantes. Além da reorganização do tempo e do espaço escolar, interessa diretamente ao nosso texto, a política de parcerias com empresas e outras instituições privadas, via Associação de Pais e Mestres, que representou o aprofundamento e inovação das modalidades de privatização no âmbito da educação. Essa política indicou o desenvolvimento de atividades de manutenção predial, programas artísticos e \ou esportivos no contra turno escolar, além das aquisições de materiais. Por possuírem personalidade jurídica privada, essas associações de pais e mestres funcionavam como "porta de entrada" de outras instituições privadas, em especial, os chamados parceiros organizados na sociedade civil que teriam como tarefa a elaboração de programas junto às escolas, aplicação e gerenciamento de recursos financeiros e quiçá, pessoais, para atuar em diversas frentes nas escolas públicas (ADRIÃO, 2008).

Outras evidências dessa privatização da oferta educacional: o crescimento de convênios em cidades de pequeno porte no interior do estado de São Paulo entre as prefeituras locais e as instituições de ensino privadas para o "suporte político e pedagógico" que incluía a oferta de serviços e produtos, assim como de materiais didáticos para utilização nas unidades por estudantes e docentes, incluindo apostilas e CD-ROMs; também de programas de formação continuada para docentes em serviço e de monitoramento do uso dos materiais adquiridos, incluindo aí, a organização do trabalho docente e administrativo nas escolas (ADRIÃO et al., 2009).

É possível ainda categorizarmos as evidências dessa concessão estatal às instituições educacionais privadas. De acordo com Adrião et al. (2012, p. 534), com base na "natureza" e nas

${ }^{2}$ Trata-se de uma contribuição social destinada ao financiamento de programas, projetos e ações voltados para a educação básica pública, conforme previsto no $§ 5^{\circ}$ do art. 212 da Constituição Federal de 1988. 
“consequências de parcerias firmadas entre os setores privado e governos municipais paulistas para atendimento da educação infantil e do ensino fundamental”, no período 1996 a 2006, existiam três modalidades de privatização: a subvenção pública para vagas em instituições de ensino privadas, assessoria privada para a gestão educacional e compra de "sistemas" de ensino.

A subvenção pública para vagas em estabelecimentos privados referia-se à modalidade em que os municípios, por meio de convênios com distintos formatos, repassavam recursos para instituições privadas de educação infantil, tanto para instituições privadas sem fins lucrativos, como para instituições privadas com fins lucrativos. Os primeiros eram tradicionais nesta etapa da escolaridade e os segundos constituíam outra tendência (ADRIÃO et al., 2009).

A assessoria privada para gestão educacional era entendida como a modalidade pela qual a administração pública firmava convênios ou contratos com instituições privadas, tendo por objetivo: a elaboração de orientações gerais para o funcionamento da rede escolar (Plano Municipal de Educação; estatuto do magistério; alternativas de planejamento e avaliação das escolas, entre outras); a formação de gestores das escolas e de técnicos da administração municipal; a definição de estratégias e diretrizes educacionais. Assim, como no caso da parceria para aquisição de vagas, as instituições parceiras do poder público poderiam ser privadas com e sem fins lucrativos (ADRIÃO et al., 2009).

E a aquisição de "sistemas" de ensino, "suporte político e pedagógico", conforme já mencionamos, eram constituídos por produtos e serviços elaborados por instituições privadas de ensino que disputavam a exploração mercantil educacional, por meio de órgão específico (alguns com tamanho e complexidade semelhantes ao de uma secretaria de educação) que possuía o objetivo de vender às prefeituras municipais uma variedade de produtos, de maneira a atender todas as etapas de escolaridade que estivessem sob a responsabilidade do município-cliente (ADRIÃO et al., 2009).

Após situarmos historicamente as transformações nas formas de privatização na oferta do direito à educação, a seguir analisaremos, dentro do seu contexto de produção, os números da pesquisa censitária produzida pelo IBGE em parceria com o IPEA produzido em 2005.

\section{O crescimento e a intensificação na atuação de FASFIL.}

O campo Educação e Pesquisa do Censo 2005 IBGE-IPEA possuía 19.940 FASFIL, 5,9\% do total, com sete subdivisões:

Tabela 1: números absolutos e relativos de entidade por subdivisão

\begin{tabular}{l|l|l}
\hline Subcampos & Número de entidades & Número Percentual (\%) \\
\hline Educação infantil & 3.154 & 0,9 \\
\hline Ensino fundamental & 7.910 & 2,3 \\
\hline Ensino médio & 1.448 & 0,4 \\
\hline Ensino superior & 2.152 & 0,6 \\
\hline Estudos e pesquisas & 2.441 & 0,7 \\
\hline Educação profissional & 447 & 0,1 \\
\hline Outras formas de Educação/ensino & 2.388 & 0,7 \\
\hline Total & $\mathbf{1 9 . 9 4 0}$ & $\mathbf{5 , 9}$
\end{tabular}

Fonte: elaborada pelos autores 
Tais dados sugerem que a educação básica (educação infantil, ensino fundamental e médio), nosso recorte para análise, com disparidade entre suas etapas constitutivas, continha mais da metade do total de FASFIL atuando no campo Educação e Pesquisa.

Tais disparidades sugerem que a educação infantil e o ensino fundamental foram o alvo de investimentos e parcerias público-privadas, justamente porque foi também nesse período que a política educacional privilegiou essas etapas da educação básica comprando vagas e concedendo financiamento às escolas privadas, principalmente no âmbito da educação infantil e por meio de assessorias na gestão e aquisição de "sistemas" de ensino no âmbito do ensino fundamental (PINTO, 2016; ADRIÃO et al., 2012).

No Censo 2005 IBGE-IPEA verificamos um crescimento nos postos de trabalho assalariados nas FASFIL no campo Educação e Pesquisa: de 301.022 em 1996, para 446.965 em 2002 (crescimento expressivo de 48,5\%) e 509.265 em 2005 (salto de 13,9\% em relação ao ano de 2002). Em especial nos subcampos da Educação Básica verificamos as mesmas disparidades explicadas no parágrafo anterior:

Tabela 2. Número de trabalhadores/Ano por subcampo (Educação básica)

\begin{tabular}{l|l|l|l}
\hline Subcampos (Educação básica) & $\begin{array}{l}\text { Número de } \\
\text { trabalhadores/1996 }\end{array}$ & $\begin{array}{l}\text { Número de } \\
\text { trabalhadores/2002 }\end{array}$ & $\begin{array}{l}\text { Número de } \\
\text { trabalhadores/2005 }\end{array}$ \\
\hline Educação infantil & 12.686 & 20.192 & 25.285 \\
\hline Ensino Fundamental & 74.276 & 97.997 & 107.070 \\
\hline Ensino médio & 57.844 & 62.079 & 66.834 \\
\hline
\end{tabular}

Fonte: elaboração os autores.

Sendo mais específico, no subcampo "Educação Infantil” a variação com base em número relativo foi de 59\% entre 1996 e 2002 e de consideráveis 25,2\%, por se tratar de um intervalo de apenas três anos, em relação a 2002 e 2005. Por sua vez, no âmbito do ensino fundamental e médio a variação do número de postos de trabalho foi menor em relação à educação infantil. Nas FASFIL do ensino fundamental, entre os anos de 1996 e 2002 a variação foi de apenas $26,6 \%$ e 13,9\% entre 2002 e 2005. Já as FASFIL de ensino médio a variação do número de trabalhadores foi de 7,3\% entre 1996 e 2002 e 7,7\% entre os anos de 2002 e 2005.

Como mostra Melo (2018), a expansão de uma série de legislações municipais e estaduais, além das aprovadas em âmbito federal no final dos anos 1990 nos Governos Fernando Henrique Cardoso (1995-2002), contribuiu para esse aprofundamento da privatização de políticas públicas com diferentes proveniências.

Ao que tudo indica, tais números seguiam a tendência apontada pelo censo educacional do período que demonstrava a concentração de professores nos estabelecimentos de ensino voltados para a educação infantil e ensino fundamental em detrimento do ensino médio. Esses números ainda indicavam que a idade desses trabalhadores da educação variava entre 28 e 42 anos, mas com a predominância dos mais novos entre a educação infantil e o ensino fundamental e maior concentração de professores licenciados no âmbito do ensino médio (BRASIIL, 2009).

A plausibilidade dessas informações reside na expansão da escolarização no Brasil daquele período, algo que representou uma abertura de portas, o fechamento de outras, à conquista de oportunidades educacionais, em especial, para os setores mais pauperizados da população (BEISIGEL,1996). 
No tocante à distribuição regional das FASFIL verificamos naquele contexto de publicação do Censo 2005 IBGE-IPEA o seguinte quadro:

Tabela 3. Distribuição regional de FASFIL/etapa da Educação Básica.

\begin{tabular}{l|l|l|l|l|}
\hline Regiões do País & Educação Infantil & Ensino Fundamental & Ensino Médio & Total \\
\hline Norte & 75 & 414 & 51 & 540 \\
\hline Nordeste & 382 & 2.009 & 314 & 2.705 \\
\hline Sudeste & 1.832 & 3.280 & 659 & 5.771 \\
\hline Centro-oeste & 254 & 592 & 118 & 964 \\
\hline Sul & 611 & 1.615 & 306 & 2.532 \\
\hline Total & 2.900 & 7.910 & 1.448 & \\
\hline
\end{tabular}

Fonte: elaboração dos autores.

Podemos verificar diante desses números uma concentração de FASFIL na região sul e sudeste do país naquele contexto de publicação do censo em 2005. Isso ocorria em virtude do maior poderio econômico dessas duas regiões em relação ao cenário nacional. Tais números ainda podem expressar que existe uma assimetria entre as regiões no que diz respeito às oportunidades educacionais oferecidas, mediante repasse de verbas públicas, via FASFIL. Onde existe a maior concentração de renda, tendencialmente, existe um número maior de oportunidades educacionais (CASTRO, 2009).

Vejamos agora a partir do Censo 2005 IBGE-IPEA o detalhamento a respeito do tempo de existência das FASFIL, considerando (por proximidade) as suas décadas de criação:

Tabela 4. Tempo de existência das FASFIL/etapa da educação básica.

\begin{tabular}{l|l|l|l|l}
\hline Tempo de existência das FASFIL & Educação Infantil & Ensino Fundamental & Ensino Médio & Total \\
\hline Anterior a 1970 & 116 & 596 & 367 & 1.079 \\
\hline Ao longo dos anos 1970 & 290 & 922 & 329 & 1.541 \\
\hline Nos anos 1980 & 790 & 1.224 & 206 & 2.220 \\
\hline Nos anos 1990 & 1.286 & 3.698 & 393 & 5.377 \\
\hline Anos 2000 (até 2005) & 672 & 1.470 & 163 & 2.305 \\
\hline
\end{tabular}

Fonte: elaboração dos autores.

Tal continuidade no crescimento ao longo do período evidencia que existia uma conjuntura política e econômica favorável a isso. No entanto, a maior concentração desse crescimento entre os anos 1990 e 2000 é forte indicativo de uma intensificação dessa conjuntura no bojo da implantação do projeto neoliberal no Brasil, a partir da reforma do Estado brasileiro com a ação do Ministério da Administração e Reforma do Estado (MARE) que buscou redefinir o papel do Estado naquilo que dizia respeito às suas atribuições no plano econômico e social. Em vez de responsável direto pela produção de bens e execução de políticas sociais, o Estado seria nessa redefinição o promotor e regulador desse desenvolvimento por meio de formas diversas de privatização. Especialmente nas políticas públicas os mecanismos de convênios com organismos privados, com ou sem fins de lucro, respondiam por essa expansão (BRASIL, 1995). 
Esse redimensionamento, na verdade, conduziu o Estado a uma suposta profissionalização das suas agências por meio de um enfoque "gerencial", voltado para o "cliente", para os "resultados", para a "qualidade do output" e não para a fidelidade às normas. Não se tratava apenas de uma reforma administrativa, muito menos, de uma abertura do Estado para a sociedade civil, ao contrário, tratou-se de uma liberação da máquina do Estado do universo alegadamente burocrático (MORAES, 2002).

Cury (2003, p. 150) afirmava que dinâmica neoliberal "entronizadora do mercado como o novo bezerro de ouro" aprofundou ainda mais os mecanismos de exclusão social nos países periféricos, caso do Brasil. Ademais, o autor também afirmava que: circunscritos pela pressão das agências internacionais, cerceados pela anomia social interna, países como o Brasil, periféricos, onde nem bem o Estado chegou aos seus mais diversos rincões para executar suas atribuições clássicas, foram constituídos, no contexto da década de 1990, pelos governos concepções e práticas do "Estado mínimo", cujo volume de agências especiais para lidar com as suas atribuições cresceu exponencialmente.

É emblemático que, mesmo não sendo muito numerosas (19.940), as FASFIL do campo Educação e Pesquisa concentrassem, naquele período, elevado número de pessoal ocupado/ trabalhadores. Representando apenas 5,9\% das FASFIL no Brasil, elas possuíam 29,8\% do total de trabalhadores e trabalhadoras. Essa concentração era ainda maior no subgrupo Educação Superior, onde menos de 1\% das FASFIL (2.152 entidades) empregavam quase 240 mil trabalhadores, representando perto de $14 \%$ de todos empregados do universo de FASFIL e 47,1\% do grupo Educação e Pesquisa.

Tal quadro é possível pelo fato de ser o crescimento do ensino superior, via transferência de recursos públicos para instituições privadas, o objetivo prescrito pelo relatório do Banco Mundial, "O Ensino Superior: as lições derivadas da experiência", aos países em desenvolvimento. De acordo com o documento, naquele momento, aos países submetidos aos ajustes e às restrições fiscais previstas pelo Banco Mundial, como medidas para as retiradas de empréstimos, caberia o aumento do número de matrículas no ensino superior via "diferenciação das instituições" (instituições privadas) a partir de um gasto supostamente eficiente do dinheiro público (BANCO MUNDIAL, 1995).

Nos outros subcampos, a presença de trabalhadores nas FASFIL também era expressiva, algo que revela uma dinâmica de transferência de recursos públicos na Educação Básica de forma simultânea à Educação Superior, mesmo que em menor intensidade. Vejamos na tabela abaixo:

Tabela 5. Numero absoluto e relativo de trabalhadores por etapa da Educação Básica.

\begin{tabular}{l|l|l|l}
\hline Subcampo & $\begin{array}{l}\text { Número absoluto } \\
\text { de Trabalhadores }\end{array}$ & $\begin{array}{l}\text { Numero relativo ao campo } \\
\text { Educação e Pesquisa (\%) }\end{array}$ & $\begin{array}{l}\text { Número relativo ao } \\
\text { total de FASFIL (\%) }\end{array}$ \\
\hline Educação Infantil & 25.285 & 5 & 1,5 \\
\hline Ensino Fundamental & 107.070 & 21 & 6,3 \\
\hline Ensino Médio & 66.834 & 13,1 & 3,9 \\
\hline
\end{tabular}

Fonte: elaboração dos autores.

Cumpre registrar que esses números da Educação Infantil, ensino Fundamental e Ensino Médio demandam maiores análises, visto ser comum na oferta educacional brasileira que a mesma unidade educacional ofereça mais de uma etapa da educação básica. Isso quer dizer que 
não seria difícil localizarmos unidades educacionais que atuavam no período em que o censo foi publicado em três ou duas etapas. Se for possível vislumbrar unidades específicas na Educação Infantil, no tocante ao Ensino Fundamental e ao Ensino Médio isso era mais difícil.

Ao mesmo tempo, é importante ter em conta que isso não significava que todas as FASFIL do campo "Educação e Pesquisa" possuíam trabalhadores assalariados. Segundo o censo, 268.887 FASFIL (79,5\% do total) não possuíam nenhum trabalhador assalariado. Especificamente no campo "Educação e Pesquisa", 11.563 FASFIL, de um total de 19.940, não possuíam trabalhadores assalariados. Ou seja, enquanto na média nacional 79,5\% das FASFIL não possuíam trabalhadores assalariados, no campo "Educação e Pesquisa" esse percentual caía para 57,9\%.

Isso ocorria, assim acreditamos, em virtude da natureza das atividades desempenhadas que, em geral, partiam de convênios com entes estatais, via FASFIL, para a prestação de serviços educacionais conforme aqueles enumerados por Adrião et al (2009): subvenção pública de vagas em escolas privadas, prestação de serviços relativos à gestão educacional e aquisição de sistemas de ensino, por exemplo.

Nesse caso, o número de funcionários que essas agências intermediadoras possuíam no período em que o Censo foi realizado nos informa, em alguma medida, o lastro mercantilista no âmbito da oferta do direito à educação.

Tabela 6. Quantidade de trabalhadores/Número absoluto de FASFIL no Campo Educação e Pesquisa e relativo ao total de FASFIL.

\begin{tabular}{l|l|l}
\hline $\begin{array}{l}\text { Quantidade de } \\
\text { Trabalhadores }\end{array}$ & $\begin{array}{l}\text { Número de FASFIL no campo } \\
\text { "Educação e Pesquisa" }\end{array}$ & $\begin{array}{l}\text { Número relativo ao total de } \\
\text { FASFIL (\%) }\end{array}$ \\
\hline 1 a 2 & 1.188 & 5,9 \\
\hline 10 a 49 & 3.275 & 16,4 \\
\hline 50 a 99 & 1.032 & 5,2 \\
\hline 100 a 499 & 896 & 4,5 \\
\hline+ de 500 & 152 & 0,8 \\
\hline
\end{tabular}

Fonte: elaboração dos autores.

O próximo passo desse detalhamento referente às FASFIL no campo "Educação e Pesquisa", em especial na Educação Básica, no Brasil com base no Censo produzido pelo IBGE em parceria com o IPEA em 2005 será analisarmos a distribuição de trabalhadores por região no país.

Tabela 7. Número absoluto de trabalhadores por etapa da Educação Básica/Região do País

\begin{tabular}{l|l|l|l|l}
\hline Regiões do País & $\begin{array}{l}\text { Número absoluto de } \\
\text { Trabalhadores na } \\
\text { Educação Infantil }\end{array}$ & $\begin{array}{l}\text { Número absoluto de } \\
\text { Trabalhadores no } \\
\text { Ensino Fundamental }\end{array}$ & $\begin{array}{l}\text { Número absoluto de } \\
\text { Trabalhadores no } \\
\text { Ensino Médio }\end{array}$ & Total \\
\hline Norte & 544 & 3.471 & 1.725 & 5.740 \\
\hline Nordeste & 1.449 & 16.002 & 12.288 & 29.739 \\
\hline Sudeste & 17.503 & 51.614 & 33.528 & 102.645 \\
\hline Centro-oeste & 1.802 & 10.252 & 4.244 & 16.298 \\
\hline Sul & 3.987 & 25.731 & 15.049 & 44.767 \\
\hline
\end{tabular}

Fonte: elaboração dos autores. 
Mais do que um número absoluto, a média de trabalhadores por FASFIL em cada região do país em comparação com a média nacional permite mensurarmos o tamanho das FASFIL no campo "Educação e Pesquisa" em 2005, uma vez que, salvo problemas só detectáveis em análises pormenorizadas de cada caso concreto, o número de funcionários era proporcional à abrangência da atuação de cada entidade.

As FASFIL, de acordo com o Censo, possuíam em média 25,5 funcionários, sendo que: “Educação Infantil” (8,0); b) “Educação fundamental $(13,5)$ "; c) "Ensino Médio" $(46,5)$. Já no tocante a divisão regional há disparidades em relação à média nacional.

Tabela 7. Média de trabalhadores por FASFIL no campo Educação Pesquisa e nos subcampo Educação Infantil, Ensino Fundamental e Médio/Região do País

\begin{tabular}{l|l|l|l|l}
\hline $\begin{array}{l}\text { Regiões } \\
\text { do País }\end{array}$ & $\begin{array}{l}\text { Média de } \\
\text { trabalhadores por } \\
\text { FASFIL no campo } \\
\text { Educação e Pesquisa }\end{array}$ & $\begin{array}{l}\text { Média de } \\
\text { trabalhadores por } \\
\text { FASFIL no subcampo } \\
\text { Educação Infantil }\end{array}$ & $\begin{array}{l}\text { Média de } \\
\text { trabalhadores por } \\
\text { FASFIL no subcampo } \\
\text { Ensino Fundamental }\end{array}$ & $\begin{array}{l}\text { Média de } \\
\text { trabalhadores por } \\
\text { FASFIL no subcampo } \\
\text { Ensino Médio }\end{array}$ \\
\hline Norte & 22,4 & 7,3 & 8,4 & 7,3 \\
\hline Nordeste & 16 & 3,8 & 8 & 39,1 \\
\hline Sudeste & 29 & 9,6 & 15,7 & 50,9 \\
\hline $\begin{array}{l}\text { Centro- } \\
\text { oeste }\end{array}$ & 16 & 7,1 & 17,3 & 36 \\
\hline Sul & 25,8 & 6,5 & 15,9 & 49,2 \\
\hline
\end{tabular}

Fonte: elaboração dos autores.

Tais números demonstram mais uma vez a desigualdade entre as regiões do país. A concentração de trabalhadores nas regiões sul e sudeste, sempre acima da média nacional, a não ser no caso da educação infantil na região sul, evidenciam o quanto elas desequilibram a oferta de oportunidades educacionais no Brasil, em função do seu maior poderio econômico e social. Isso significa que a probabilidade de dividendos para o setor privado que investe em educação nessas regiões é maior do que outras regiões e isso do ponto de vista da mercantilização da educação é o eixo que norteia todo processo (ROBERTSON; VERGER, 2012).

Além do mais, em que pesem as desigualdades regionais, outro dado que chama atenção é a elevada média de trabalhadores no âmbito do ensino médio que pode estar relacionada ao crescimento marginal do número de matrículas nessa etapa da educação básica, em virtude do processo de universalização do ensino fundamental iniciado nos anos 1990. Inferimos também, como consequência desse processo marginal de crescimento que a inadequação dessa etapa em relação ao crescimento, já que ele foi marginal, acarretou níveis elevados de evasão escolar, por diferentes motivos, algo que acabou criando um farto espaço de atuação para as FASFIL, como forma de prestação de serviços visando à (suposta) melhora da qualidade educacional (COSTA, 2013).

Ademais, um quadro interessante foi revelado quando analisamos a remuneração média dos trabalhados nas FASFIL. Os 1.709.156 trabalhadores assalariados nas 338.162 FASFIL recebiam em média 3,8 salários mínimos por mês, um pouco acima dos trabalhadores em geral cadastrados no CEMPRE do Ministério do Trabalho em 2005. Especificamente no campo "Educação e Pesquisa" há um profundo desequilíbrio da média salarial entre os subcampos, embora o conjunto desse 
campo esteja bem acima da média salarial nacional, onde os seus trabalhadores recebem algo em torno de 5,1 salários mínimos mensais. Os trabalhadores e, sobretudo, trabalhadoras, face ao grande contingente de mulheres que atuam com "Educação Infantil" no país, recebem nas FASFIL desse subcampo, uma média de 2,0 salários-mínimos mensal, muito menor que média nacional e assustadoramente menor que a média do conjunto desse campo (5,1 salários). Aliás, esse subcampo em relação aos outros é o que pior remunera em média seus trabalhadores. Já no subcampo "Ensino Fundamental", a média salarial aproxima-se da média nacional geral com 3,6 salários mínimos mensais para cada trabalhador. No subcampo "Ensino Médio" essa média salarial já apresentava em 2005 uma elevação em relação à média nacional alcançando 4,6 salários mínimos.

Esse quadro ganha novos contornos quando acrescentamos as variações regionais. Assim, há uma considerável disparidade em termos nacionais no tocante à remuneração média dos trabalhadores nas FASFIL por região, cuja variação vai de 3,6 salários mínimos na região nordeste a 5,6 salários na região Sudeste, onde os trabalhadores obtêm em média maior remuneração.

Cumpre lembrar que no campo "Educação e Pesquisa" as médias salariais são maiores que as médias das FASFIL em geral. Contudo, como já era de se esperar, a multiplicidade do campo implica não só nas disparidades regionais, mas dentre os próprios subcampos. Nas FASFIL que atuam com Educação Infantil, a média salarial na região Nordeste atinge 1,4 salários mínimos. Curiosamente, e destoando consideravelmente do relatório tanto em termos nacionais gerais e do próprio campo "Educação e Pesquisa", a região que possui maiores médias salariais no âmbito das FASFIL de Educação Infantil é a região Norte, com 2,6 salários mínimos, ao passo que em geral nos outros subcampos eram as regiões Sul ou Sudeste. No subcampo Ensino Fundamental, enquanto na Região Nordeste os trabalhadores recebem em média 2,6 salários mínimos, aqueles que atuam na região Sudeste recebem 4,2 salários mínimos. Já no subcampo "Ensino Médio" essa variação segue severa, já que a média salarial da região que melhor remunera (sudeste) atinge 5,5 salários, enquanto a de menor remuneração (Nordeste) atinge 2,7 salários mínimos aos trabalhadores que atuam nessas FASFIL.

\section{Considerações finais}

Os dados apresentados pelo Censo relativo às FASFIL produzido pelo IBGE em parceria com o IPEA (2005), como mostramos por meio da tabulação, permitem inferências sobre o aprofundamento do projeto neoliberal no Brasil. A expansão do número, o aumento da amplitude e o crescimento vertiginoso da capacidade de atuação dessas entidades está diretamente ligado às maiores possibilidades de acesso ao fundo público trazido por mudanças legislativas tanto no plano federal, como em estados e municípios. As chamadas leis das Organizações Sociais (OS) e das Organizações da Sociedade Civil de Interesse Público (OSCIP) viabilizaram contratos de longa duração entre os executivos dos diferentes entes federados e FASFIL, tal qual emanado por longo tempo em diversos documentos de organismos internacionais. Essa é a fase, assim inferimos, do desenvolvimento do projeto neoliberal que confere novas características as relações público-privadas na oferta do direito à educação.

Em outros momentos da história educacional brasileira, como também demonstramos, as relações público-privadas tinham outras características, principalmente naquilo que se refere à sua capilaridade e impacto na oferta do direito à educação. Todavia a característica que ainda permanece comum nesse processo histórico é a política adotada pelo conjunto das classes 
dominantes brasileiras que concede e estimula o desenvolvimento de um setor privado no campo da educação extremamente robusto. Esse processo ganhou novos contornos com a atuação empresarial direta, por meio de organismos de diversos tipos, também no âmbito da formulação e execução das políticas adotadas. Podemos mencionar o processo de organização desse setor em torno do Movimento “Todos pela Educação”, onde uma série de empresas multinacionais amalgamam forças para fazer valer os seus interesses.

Ademais, vale destacar também que pesquisa censitária relativa às FASFIL produzido pelo IBGE em parceria com o IPEA (2005) é um documento datado e que, possivelmente, em versões mais atuais, outros quadros analíticos podem ser desenvolvidos, algo que, em alguma medida, confere (des)continuidades ao que verificamos. Em outras palavras é possível inferirmos que as transformações na relação público-privado na oferta do direito à educação ocorrerão, contudo, o seu eixo norteador, o acesso ao fundo público, como forma de viabilizar a lucratividade, permanecerá com a novidade de um intenso ataque à coisa pública, agora reorientada sob a falácia de serviço público prestado por organismo privado.

\section{Referências}

ADRIÃO, T. Oferta do ensino fundamental em São Paulo: um novo modelo. Educ. Soc., Campinas, vol. 29, n. 102, p. 79-98, jan. / abr. 2008. Disponível em: https://www.scielo.br/scielo.php?script=sci_ arttext\&pid=S0101-73302008000100005 Acesso em 25 de mar. 2021.

ADRIÃO, T; Et al. Uma Modalidade Peculiar de Privatização da Educação Pública: a aquisição de “sistemas de ensino" por municípios paulistas. Educ. Soc., Campinas, vol. 30, n. 108, p. 799-818, out. 2009. Disponível em: https://www.scielo.br/scielo.php?pid=S0101-73302009000300009\&script=sci_ abstract\&tlng=pt Acesso em 25 de mar. 2021.

ADRIÃO, T; Et al. As Parcerias entre prefeituras paulistas e o setor privado na política educacional: expressão de simbiose? Educ. Soc., Campinas, v. 33, n. 119, p. 533-549, abr.-jun. 2012. Disponível em: https://www.scielo.br/scielo.php?pid=S0101-73302012000200011\&script=sci_abstract\&tlng=pt Acesso em: 25 de mar. 2021.

BANCO MUNDIAL. La enseñansa superior: las lecciones derivadas de la experiência. Washington: Banco Mundial: 1995.

BEISEGEL, Celso Ruy. Qualidade do ensino na escola pública. São Paulo. Liber Livro Editora,1986.

BRASIL. Presidência da República. Plano diretor da reforma do aparelho do Estado. Brasília, 1995.

BRASIL. Lei Federal 9.637 de 15 de maio de 1998. Dispõe sobre a qualificação de entidades como organizações sociais, a criação do Programa Nacional de Publicização, a extinção dos órgãos e entidades que menciona e a absorção de suas atividades por organizações sociais, e dá outras providências. Diário Oficial da União, 18 de mai. 1998. Disponível em: encurtador.com.br/GHKU1

BRASIL. Lei Federal 9.790 de 23 de março de 1999. Dispõe sobre a qualificação de pessoas jurídicas de direito privado, sem fins lucrativos, como Organizações da Sociedade Civil de Interesse Público, institui e disciplina o Termo de Parceria, e dá outras providências. Diário Oficial da União, 24 de marc. 1999. Disponível em: encurtador.com.br/fjLOZ

BRASIL. Estudo exploratório sobre o professor brasileiro com base nos resultados do Censo Escolar da Educação Básica 2007. Brasília: INEP, 2009. 
CASTRO, J. A. Evolução e desigualdade na educação brasileira. Educ.

Soc. vol.30 n.108 Campinas Oct. 2009. p.673-697. Disponível em: https://www.scielo.br/pdf/es/ v30n108/a0330108.pdf Acesso em 25 de mar. 2021.

COSTA, G. L. M. O ensino médio no Brasil: desafio à matricula e ao trabalho docente. R. bras. Est. pedag., Brasília, v. 94, n. 236, p. 185-210, jan./abr. 2013. Disponível em: https://www.scielo.br/scielo. php?pid=S2176-66812013000100010\&script=sci_abstract\&tlng=pt Acesso em 25 de mar. 2021.

CURY, C. R. J. Políticas da educação: um convite ao tema. FAVERO, O; SEMERARO, G. (orgs.) Democracia e construção do público no pensamento educacional brasileiro. Petrópolis-RJ: Vozes, 2003. Pp. 147-162

CURY, C. R. J. Um novo movimento da educação privada. In: ADRIÃO, T. e PERONI, V. (orgs.). Público e privado na Educação: novos elementos para o debate. São Paulo: Xamã, 2008.

CUNHA, L. A. Educação e desenvolvimento social no Brasil. Rio de Janeiro, Francisco Alves, 1980.

DAVIES, Nicholas. Verbas da Educação: o legal e o real. Niterói: EDUFF; 2000.

FRIGOTTO, G.. Educação e a construção democrática no Brasil - da ditadura civil militar à ditadura do capital. In FAVERO, O; SEMERARO, G. (org.). Democracia e e construção do público no pensamento educacional brasileiro. Petrópolis-RJ: Vozes, 2003.

MARTINS, A. "Todos pela educação": o Projeto Educacional de Empresários para o Século XXI. Caxambu-MG: Anais da Reunião anual da ANPED, 2008.

MANCEBO, D; VALE, A. A; MARTINS, T. B. Políticas de expansão da educação superior no Brasil 19952010. Revista Brasileira de Educação v. 20 n. 60 jan.-mar. 2015. Disponível em: https://www.scielo. $\mathrm{br} / \mathrm{pdf} / \mathrm{rbedu} / \mathrm{v} 20 \mathrm{n60} / 1413-2478-\mathrm{rbedu}-20-60-0031 . p d f$ Acesso em 25 de mar. 2021.

MORAES, R. C. Reformas neoliberais e políticas públicas. Hegemonia ideológica e redefinição das relações Estado-sociedade. Educ. Soc. v. 23, n .80. Campinas, set.2002. p. 13-24. Disponível em: https://www.scielo.br/scielo.php?pid=S0101-73302002008000002\&script=sci_abstract\&tlng=pt Acesso em 25 de mar. 2021.

MELO, M. P. A lei das Organizações Sociais na cidade do Rio de Janeiro e a efetivação do projeto neoliberal: Uma análise crítica da Lei 5026 2009 e do Decreto 30780 \2009. Emancipação, Ponta Grossa, 18(1): 125-136, 2018. Disponível em: https://revistas2.uepg.br/index.php/emancipacao/article/ view/10163/209209210050 Acesso em 25 de mar. 2021.

PAOLI, Maria Celia. O mundo indistinto: sobre gestão, violência e política. OLIVEIRA, Francisco e RIZEK, Cibele Saliba. (orgs). A Era da Indeterminação. São Paulo: Boitempo, 2007. pp. 221-256.

PINTO, J. M. P. Uma análise da destinação dos recursos públicos, direta ou indiretamente, ao setor privado de ensino no brasil. Educ. Soc., Campinas, v. 37, nº. 134, p.133-152, jan. / mar., 2016. Disponível em: https://www.scielo.br/pdf/es/v37n134/1678-4626-es-37-134-00133.pdf Acesso em 25 de mar. 2021.

ROBERTSON, S.; VERGER, A. A origem das parcerias público-privada na governança global da educação. Educ. Soc. vol. 33, no 121, Campinas Oct./Dec 2012. p.1133-1156. Disponível em: https://www.scielo. br/scielo.php?pid=S0101-73302012000400012\&script=sci_abstract\&tlng=pt Acesso em 25 de mar. 2021.

SAVIANI, D.. A nova lei de educação. São Paulo, Autores Associados, 1998. 
SAVIANI, D. A escola pública brasileira no longo século XX (1890-2001). In III Congresso Brasileiro de História da Educação. Sessão de Comunicação Coordenada: “O século XX brasileiro: da universalização das primeiras letras ao Plano Nacional de Educação (1890-2001)”. Curitiba, 7 a 10 de novembro de 2004.

SAVIANI, Demerval. Plano de desenvolvimento da educação: analise do projeto do MEC. Educ. e Soc.. Campinas - SP: vol. 28, n. 100, p. 1231-1255, out. 2007. Disponível em: https://www.scielo.br/pdf/es/ v28n100/a2728100.pdf Acesso em 25 de mar. 2021.

SHIROMA, E. O; GARCIA, R.M.C; CAMPOS, R.F. Conversão das 'almas' pela liturgia da palavra: uma análise do discurso do movimento Todos pela Educação. In: BALL, S e MAINARDES, J. (orgs) Políticas educacionais, questões e dilemas. S.Paulo, Cortez editora, 2011. p.222 - 247.

XAVIER, L. N. Oscilações do público e do privado na história da educação brasileira. Revista Brasileira de História da Educação (RBHE), n 5 jan. / jun. 2003. 233-252. Disponível em: https://periodicos. uem.br/ojs/index.php/rbhe/article/view/38718/20247 Acesso em 25 de mar. 2021. 